\title{
EFEITO DA PROFUNDIDADE DE ADUBAÇÃO E SEMEADURA NA CULTURA DO MILHO
}

\author{
Hingrid Raiany Santos Teixeira ${ }^{1 *}$, Edivania de Araujo Lima ${ }^{2}$, Fábio Mielezrski ${ }^{3}$, Alexandre \\ Faria da Silva ${ }^{4}$, Augusto Matias de Oliveira ${ }^{5}$ \\ ${ }^{1}$ Mestrando do Programa de pós graduação em Agronomia/Fitotecnia - Grandes Culturas, Universidade \\ Federal do Piauí. Bom Jesus - PI. *E-mail do autor correspondente: hingridteixeira.agro@gmail.com \\ ${ }^{2}$ Prof $^{a}$. Doutora da Universidade Federal do Piauí - CPCE, Bioclimatologia Vegetal, Bom Jesus - PI. \\ ${ }^{3}$ Prof $^{\circ}$. Doutor do Centro de Ciências Agrárias, Universidade Federal da Paraíba. Grandes Culturas. Areia - \\ PB. \\ ${ }^{4}$ Pós Doutorando do Programa de pós graduação em Agronomia/Fitotecnia. Fitotecnia/ Manejo e Técnicas \\ Culturais. Universidade Federal do Piauí, Bom Jesus - PI. \\ ${ }^{5}$ Mestrando do Programa de pós graduação em Agronomia/Fitotecnia - Fitopatologia. Universidade Federal do \\ Piauí. Bom Jesus - PI.
}

RESUMO: O milho é considerado uma das principais espécies utilizadas no Brasil sendo a profundidade de semeadura e de adubação, assim como sua adequada uniformidade e distribuição são alguns dos fatores que mais influenciam na emergência e no desenvolvimento vegetativo da cultura. $\mathrm{O}$ objetivo desse trabalho foi identificar a influência da profundidade de semeadura e adubação no desenvolvimento inicial do milho. O experimento foi conduzido na área experimental do Campus Professora Cinobelina Elvas UFPI sendo distribuído em esquema fatorial $(2 \times 3)+2$, num delineamento inteiramente casualizado, com os tratamentos: duas profundidades de semeadura $(3$ e $5 \mathrm{~cm}$ ), três profundidades de adubação $(6,12$ e $18 \mathrm{~cm})$ e testemunha para as profundidades de 3 e $5 \mathrm{~cm}$ de semeadura que não receberam adubo, cada tratamento com três repetições, totalizando 24 repetições. O experimento foi conduzido em vasos no período de outubro a janeiro de 2016, com o híbrido de milho PIONNER 30F53VYH. Foi utilizado para adubação $500 \mathrm{~kg} \mathrm{ha}^{-1}$ do adubo formulado 8-20-20 e $150 \mathrm{~kg} \mathrm{ha}^{-1}$ de ureia, totalizando $107,5 \mathrm{~kg} \mathrm{ha}^{-1}$ de nitrogênio, $100 \mathrm{~kg} \mathrm{ha}^{-1}$ de $\mathrm{P}_{2} \mathrm{O}_{5}$ e $100 \mathrm{~kg} \mathrm{ha}^{-1}$ de $\mathrm{K}_{2} \mathrm{O}$, aplicado no sulco do plantio. Foram analisados: comprimento da parte aérea, diâmetro do colmo, matéria seca das raízes e da parte aérea. Os resultados mostram que para altura de planta, diâmetro do colmo, matéria seca da parte aérea, a profundidade de $6 \mathrm{~cm}$ de profundidade de deposição do adubo e semeadura a $3 \mathrm{~cm}$ apresentaram as maiores médias. Para todos os tratamentos a semeadura a $3 \mathrm{~cm}$ foi superior enquanto a testemunha foi quem apresentou as menores médias.

Palavras-chave: Híbrido. Diâmetro do colmo. Adubação.

\section{EFFECT OF THE DEPTH OF FERTILIZATION AND SOWING IN CORN CULTURE}

ABSTRACT: Maize is considered one of the main species used in Brazil, being the depth of sowing and fertilization, as well as its adequate uniformity and distribution are some of 
the factors that most influence the emergence and the vegetative development of the crop. The objective of this work was to identify the influence of sowing depth and fertilization on the initial corn development. The experiment was conducted in the experimental area of the Campus Professor Cinobelina Elvas - UFPI and was distributed in a factorial scheme $(2 \times 3)$ +2 in a completely randomized design with treatments: two sowing depths $(3$ and $5 \mathrm{~cm})$, three fertilization depths $(6,12$ and $18 \mathrm{~cm})$ and control for the 3 and $5 \mathrm{~cm}$ depths of nofertilizer seeding, each treatment with three replicates, totaling 24 replicates. The experiment was conducted in pots from October to January 2016, with the PIONNER $30 \mathrm{~F} 53 \mathrm{VYH}$ corn hybrid. $500 \mathrm{~kg} \mathrm{ha}^{-1}$ of formulated fertilizer 8-20-20 and $150 \mathrm{~kg} \mathrm{ha}^{-1}$ of urea

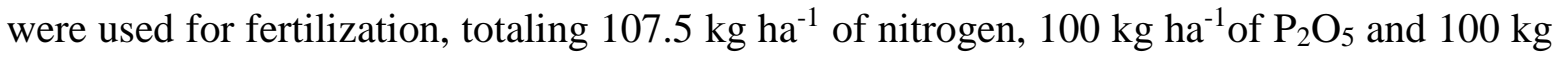
$\mathrm{ha}^{-1}$ of $\mathrm{K}_{2} \mathrm{O}$ applied to the furrow of planting. The following parameters were analyzed: aerial part length, stem diameter, dry matter weight of roots and aerial part. The results show that for plant height, stem diameter, dry weight of aerial part, the depth of $6 \mathrm{~cm}$ depth of fertilizer deposition and sowing at $3 \mathrm{~cm} \mathrm{~cm}$ presented the highest averages. For all treatments the sowing at $3 \mathrm{~cm}$ was higher while the control was the one who presented the lowest averages.

Key words: Hybrid. Stalk diameter. Fertilization.

\section{INTRODUÇÃO}

O milho (Zea mays L.) é considerado uma das principais espécies utilizadas no Brasil, visto que, anualmente, são cultivados cerca de quinze milhões de hectares, os quais contribuem para a produção de, aproximadamente, 84 milhões de toneladas de grãos (CONAB, 2016).

A importância econômica desta cultura está relacionada com várias formas de utilização, desde alimentação animal, humana até a indústria, onde é empregado como matéria-prima de diversos produtos (GUARESCHIAT et al., 2013). Seu uso em grão na alimentação animal representa a maior parte do consumo, sendo que no Brasil varia de $70 \%$ a $90 \%$ da produção total (CRUZ et al., 2011).

Um fator a ser considerado em uma operação de semeadura é a profundidade de deposição das sementes, que é condicionada pela temperatura, teor de água e tipo de solo, dentre outros fatores. A semente deve ser depositada a uma profundidade que permita um bom contato com o solo úmido, resultando em uma boa germinação. A profundidade de semeadura é um dos fatores que mais influenciam na emergência e no desenvolvimento vegetativo da cultura no milho (SILVA, 2008).

Segundo Cai et al. (2014), solos mais argilosos, com drenagem deficiente e fatores como compactação dificultam o alongamento do mesocótilo, emergência de plântulas e absorção de nutrientes e água. Nessas situações, as sementes devem ser semeadas entre 3 e 5 $\mathrm{cm}$ de profundidade (GOMES, 2016), enquanto em solos arenosos, as sementes podem ser

Cultura Agronômica, Ilha Solteira, v.27, n.1, p.91-100, 2018 
semeadas a uma maior profundidade, entre 5 e $7 \mathrm{~cm}$, para se beneficiarem do maior teor de umidade do solo (CRUZ, 2010).

A uniformidade na distribuição e profundidade de fertilizantes deve ser mantida independentemente de variações, enquanto a semeadora-adubadora deve possuir precisão nos mecanismos dosadores de sementes e fertilizantes (ANDERSSON, 2001), para não comprometer o estabelecimento da cultura no campo. O objetivo desse trabalho foi identificar a influência da profundidade de semeadura e adubação no desenvolvimento inicial na cultura do milho (CAI et al., 2014).

\section{MATERIAL E MÉTODOS}

O experimento foi conduzido na área experimental do Campus Professora Cinobelina Elvas (CPCE), da Universidade Federal do Piauí (UFPI), situado no município de Bom Jesus, Piauí, nas coordenadas geográficas 0904'28” S, 4421'31” W e altitude média de 277 m. A classificação do clima é Tropical classificado por Köppen como Cwa, com estação quente e úmido com precipitação pluvial média entre 900 e $1200 \mathrm{~mm}$ ano $^{-1}$ distribuídos entre os meses de novembro a abril.

O estudo foi desenvolvido na safra 2016-2017. O experimento foi distribuído em esquema fatorial $(2 \times 3)+2$ num delineamento inteiramente casualizado, sendo os fatores: duas profundidades de semeadura da semente $(3$ e $5 \mathrm{~cm})$, combinadas com três profundidades de deposição de adubo $(6,12$ e $18 \mathrm{~cm})$ e testemunha para as profundidades de 3 e $5 \mathrm{~cm}$ que não receberam adubo, contando cada tratamento com três repetições, totalizando 24 repetições.

O experimento foi conduzido em vasos no período de outubro a janeiro de 2016, com o híbrido de milho PIONNER 30F53VYH, escolhido por ser um híbrido que apresenta alto potencial produtivo, com sanidade foliar e de grãos, possuir bom ciclo e excelente uniformidade de planta e espiga, elevado potencial produtivo, além de apresentar alta resposta ao manejo e ser uma excelente opção para silagem (NUMMER e GRIECO, 2016).

Em cada vaso foram semeadas cinco plantas e foi realizado o desbaste no estádio V3 quando a planta apresentava três folhas totalmente desenvolvidas, deixando apenas uma planta por vaso.

Pela Tabela 1, a análise do solo antes da semeadura nos vasos apresentou os seguintes resultados.

Cultura Agronômica, Ilha Solteira, v.27, n.1, p.91-100, 2018 
Tabela 1. Caracterização química do Latossolo Amarelo distrófico pela profundidade $(\mathrm{cm})$ usado nos vasos antes da aplicação de fertilizantes:

\begin{tabular}{cc}
\hline Características & Profundidade \\
\hline $\mathrm{pH}($ água $)$ & $\mathbf{0 - 5 0} \mathbf{~ c m}$ \\
$\mathrm{P}\left(\mathrm{mg} \mathrm{dm}^{-3}\right)$ & 5,5 \\
$\mathrm{~K}^{+}\left(\mathrm{mg} \mathrm{dm}^{-3}\right)$ & 29,53 \\
$\mathrm{Ca}^{2+}\left(\mathrm{cmolcdm}^{-3}\right)$ & 120,0 \\
$\mathrm{Mg}^{2+}\left(\mathrm{cmolcdm}^{-3}\right)$ & 4,57 \\
$\mathrm{H}+\mathrm{Al}^{3+}\left(\mathrm{cmolcdm}^{-3}\right)$ & 1,56 \\
$\mathrm{SB}\left(\mathrm{cmolcdm}^{-3}\right)$ & 5,12 \\
$\mathrm{~T}\left(\mathrm{cmolcdm}^{-3}\right)$ & 6,44 \\
$\mathrm{AL}(\mathrm{cmolcdm}$ & $-3)$ \\
$\mathrm{V}(\%)$ & 11,56 \\
$\mathrm{M}(\%)$ & 0,0 \\
Matéria Orgânica $\left(\mathrm{g} \mathrm{Kg}^{-1}\right)$ & 55,7 \\
\hline
\end{tabular}

Foi utilizado para adubação $500 \mathrm{~kg} \mathrm{ha}^{-1}$ do adubo formulado 8-20-20 e $150 \mathrm{~kg} \mathrm{ha}^{-1} \mathrm{de}$ ureia que possui na sua formulação $45 \%$ de nitrogênio, totalizando $107,5 \mathrm{~kg} \mathrm{ha}^{-1} \mathrm{de}$ nitrogênio, $100 \mathrm{~kg} \mathrm{ha}^{-1}$ de $\mathrm{P}_{2} \mathrm{O}_{5}$ e $100 \mathrm{~kg} \mathrm{ha}^{-1}$ de $\mathrm{K}_{2} \mathrm{O}$. O adubo foi aplicado no sulco do plantio sob as profundidades de 6,12 e 18 centímetros de acordo com cada tratamento, com exceção a testemunha que não recebeu adubação no plantio.

O comprimento da parte aérea das plântulas foi avaliado nos estágios fenológicos de V3, V5 e V8 com auxílio de régua milimetrada, efetuando-se as medições em centímetros e os resultados foram expressos em centímetros.

O diâmetro do colmo foi mensurado com paquímetro digital Digimess ${ }^{\circledR}$, a dois centímetros do solo nos estágios fenológicos V3, V5 e V8 e os resultados foram expressos em milímetros.

A obtenção da biomassa seca das raízes foi realizada após o fim das avaliações de campo, onde as raízes foram lavadas, colocadas em sacos de papel devidamente identificados e foi realizada a secagem do material. Em seguida, foi realizada a pesagem do material em balança analítica, obtendo-se, então, a biomassa seca com precisão de $0,001 \mathrm{~g} \mathrm{e}$ o peso de cada amostra foi dividida pelo número de raízes que serão utilizadas no teste para cada amostra, obtendo-se, então, a biomassa seca média de cada tratamento.

A obtenção da biomassa seca da parte aérea também foi realizada após o fim das demais avaliações, onde as plantas sem suas respectivas raízes foram lavadas e colocadas em sacos de papel devidamente identificadas e também foi realizada a secagem do material. Após a pesagem do material em balança analítica, a biomassa seca foi obtida com precisão de $0,001 \mathrm{~g}$, após a pesagem, foi a tirada a média da biomassa seca de cada tratamento. 
O experimento foi irrigado de acordo com a exigência hídrica da cultura, respeitando a observação adicional sobre época de plantio irrigado para o estado do Piauí do híbrido de milho PIONNER 30F53VYH que recomenda que o plantio deste irrigado ocorra entre os períodos de primeiro de outubro até trinta e um de dezembro.

$\mathrm{O}$ experimento foi conduzido até o estádio V8 onde foram realizadas as últimas avalições e o material foi colhido e secado para obtenção do peso de massa seca das raízes e parte aérea, descritos anteriormente.

Os dados referentes às avaliações foram submetidos ao software R (3.1.1) para análise da variância, comparando-se as médias pelo teste de Tukey $(\mathrm{p} \leq 0,05)$, realizando uma análise de fatorial duplo em delineamento inteiramente casualizado.

\section{RESULTADOS E DISCUSSÃO}

A Tabela 2 mostra os valores médios da altura das plantas de milho no estágio V3, V5 e V8, em relação à profundidade de semeadura e de adubação.

Tabela 2. Altura das plantas em estádios fenológicos V3, V5 e V8 em função da profundidade de plantio e profundidade de deposição do adubo, CPCE/UFPI, Bom Jesus-PI.

\begin{tabular}{|c|c|c|c|c|c|c|}
\hline \multirow{2}{*}{$\begin{array}{c}\text { Profundidade } \\
\text { do Adubo }\end{array}$} & \multicolumn{6}{|c|}{ Estágio Fenológico } \\
\hline & \multicolumn{2}{|c|}{$\mathbf{V 3}$} & \multicolumn{2}{|c|}{ V5 } & \multicolumn{2}{|c|}{ V8 } \\
\hline & \multicolumn{6}{|c|}{ Profundidade de semeadura } \\
\hline & $3 \mathrm{~cm}$ & $5 \mathrm{~cm}$ & $3 \mathrm{~cm}$ & $5 \mathrm{~cm}$ & $3 \mathrm{~cm}$ & $5 \mathrm{~cm}$ \\
\hline $0 \mathrm{~cm}$ & $15 \mathrm{Da}^{1}$ & $10,6 \mathrm{Db}$ & $58 \mathrm{Ca}$ & $49 \mathrm{Cb}$ & $87,6 \mathrm{Ba}$ & $71 \mathrm{Bb}$ \\
\hline $6 \mathrm{~cm}$ & $40,66 \mathrm{Aa}$ & $35,6 \mathrm{Ab}$ & $81,6 \mathrm{Aa}$ & $74 \mathrm{Ab}$ & $124 \mathrm{Aa}$ & $120 \mathrm{Aa}$ \\
\hline $12 \mathrm{~cm}$ & $33 \mathrm{Ba}$ & $30,3 \mathrm{Ba}$ & $72 \mathrm{Ba}$ & $70 \mathrm{Aa}$ & $116 \mathrm{Aa}$ & $112 \mathrm{Aa}$ \\
\hline $18 \mathrm{~cm}$ & $26 \mathrm{Ca}$ & $21,3 \mathrm{Cb}$ & $67,6 \mathrm{Ba}$ & $60 \mathrm{Bb}$ & $116,3 \mathrm{Aa}$ & $111 \mathrm{Aa}$ \\
\hline CV\% & \multicolumn{2}{|c|}{7,4} & \multicolumn{2}{|c|}{4,16} & \multicolumn{2}{|c|}{4,37} \\
\hline
\end{tabular}

C.V.\%: coeficiente de variação experimental; ${ }^{1}$ médias seguidas de mesma letra maiúscula na coluna e minúscula na mesma linha e época não diferem entre si pelo teste de Tukey $(\mathrm{p}<0,05)$.

Pode-se observar que no estágio V3 houve diferença significativa para todos os tratamentos em relação à profundidade de deposição do adubo. $\mathrm{O}$ tratamento testemunha foi o que apresentou as menores médias de altura da planta, enquanto o melhor resultado foi obtido no tratamento que recebeu o adubo a $6 \mathrm{~cm}$ de profundidade, com as melhores médias de altura de planta para as duas profundidades de semeadura. Estes resultados podem estar relacionados a facilidade de acesso aos adubos disponíveis para a planta, proporcionando eficiência quando comparado a não aplicação. Tratamentos onde as plantas apresentam-se mais altas podem indicar que estas estejam mais bem nutridas, com maior disponibilidade de N, que as plantas de porte menor (SOUZA e FERNANDES, 2006). Estes fatores são importantes para o estabelecimento da planta no campo, o que favorece um menor ataque de pragas e plantas daninhas na cultura.

Ainda em V3, também houve diferença significativa entre as profundidades testadas, Cultura Agronômica, Ilha Solteira, v.27, n.1, p.91-100, 2018 
mostrando que para todas a profundidades de adubação a semeadura a $3 \mathrm{~cm}$ foi superior a de $5 \mathrm{~cm}$. Uma das possíveis causas desse resultado é que as plantas a $3 \mathrm{~cm}$ não enfrentaram resistência do solo para chegar até a superfície após a germinação. , além disso, profundidades maiores interferem positivamente em solos arenosos, pois possibilita maior umidade em contato com as sementes, fator essencial para germinação. Porém, como o experimento aconteceu em condições controladas, onde não houve situações de estresse hídrico, esse fator foi anulado e as sementes que estavam em uma profundidade mais superficial tiveram uma maior velocidade de germinação e portanto, mais graus dias para que pudessem se desenvolver e assim acabaram possuindo maiores médias de altura. Esse resultado se repetiu de modo geral para o estágio V5.

Entretanto, no estágio de V8, pode-se observar que a média da altura das plantas não diferiu significativamente entre si em relação a profundidade de adubação, com exceção a testemunha que apresentou médias inferiores aos demais tratamentos, isso também aconteceu comparando-se as profundidades de semeadura. Isso aconteceu porque à medida que as plantas crescem, elas tendem a uma uniformidade quanto a estabilidade da cultura no campo.

Tabela 3. Diâmetro do Colmo em estádios fenológicos V3, V5 e V8 em função da profundidade de plantio e profundidade de deposição do adubo, CPCE/UFPI, Bom Jesus-PI.

\begin{tabular}{|c|c|c|c|c|c|c|}
\hline \multirow{2}{*}{$\begin{array}{c}\text { Profundidade } \\
\text { do Adubo }\end{array}$} & \multicolumn{6}{|c|}{ Estágio Fenológico } \\
\hline & \multicolumn{2}{|c|}{$\mathbf{V 3}$} & \multicolumn{2}{|c|}{ V5 } & \multicolumn{2}{|c|}{$\mathbf{V 8}$} \\
\hline & \multicolumn{6}{|c|}{ Profundidade de semeadura } \\
\hline & $3 \mathrm{~cm}$ & $5 \mathrm{~cm}$ & $3 \mathrm{~cm}$ & $5 \mathrm{~cm}$ & $3 \mathrm{~cm}$ & $5 \mathrm{~cm}$ \\
\hline $\mathbf{0}$ & $4,8 \mathrm{Da}$ & $4,1 \mathrm{Ca}$ & $10,9 \mathrm{Da}$ & $9,1 \mathrm{Db}$ & $16,5 \mathrm{Da}$ & $13,6 \mathrm{Db}$ \\
\hline 6 & 9,6 Aa & $8,3 \mathrm{Ab}$ & $16,8 \mathrm{Aa}$ & $15 \mathrm{Ab}$ & $25,6 \mathrm{Aa}$ & $24,5 \mathrm{Ab}$ \\
\hline 12 & $7,5 \mathrm{Ba}$ & $6,5 \mathrm{Bb}$ & $14,2 \mathrm{Ba}$ & $13,4 \mathrm{Ba}$ & $23,2 \mathrm{Ba}$ & $22,5 \mathrm{Ba}$ \\
\hline 18 & $6,3 \mathrm{Ca}$ & $5,7 \mathrm{Ba}$ & $12,7 \mathrm{Ca}$ & $12 \mathrm{Ca}$ & $21 \mathrm{Ca}$ & $18 \mathrm{Cb}$ \\
\hline
\end{tabular}

C.V.\%: coeficiente de variação experimental; ${ }^{1}$ médias seguidas de mesma letra maiúscula na coluna e minúscula na mesma linha e época não diferem entre si pelo teste de Tukey $(\mathrm{p}<0,05)$.

Os resultados da tabela mostram que para os estádios V3, V5 e V8 quanto maior a profundidade de adubação menor foi o diâmetro do colmo. O colmo funciona como um depósito de sacarose que futuramente será translocado para os grãos sendo uma parte importante da planta, que sustenta as folhas e inflorescências e serve também como um órgão de reserva, acumulador de sacarose. Para Durães (2007), a reserva de açúcar no colmo da planta tem como objetivo dar resistência a possíveis distúrbios fisiológicos e fitossanitários, como estresse hídrico e incidência de doenças.

Nos tratamentos com menor profundidade de deposição do adubo, a planta teve maior disponibilidade inicial, proporcionando maior desenvolvimento vegetativo (Tabela 2). Plantas com a profundidade de adubação mais próxima a semente apresentaram maior desenvolvimento da parte aérea, proporcionando maior área foliar, favorecendo o processo 
fotossintético, obtendo maior ganho em diâmetro da planta.

É possível observar ainda que seguindo o padrão dos resultados da altura de plantas também houve diferenças entre a profundidade de semeadura e o diâmetro do colmo, sendo que os tratamentos que foram semeados a $3 \mathrm{~cm}$ de profundidade foram os tratamentos que apresentaram a maior média de diâmetro do colmo quando comparadas a semeadura a $5 \mathrm{~cm}$.

Os tratamentos que não receberam adubo foram também os que apresentaram as menores médias de diâmetro do colmo, uma vez que tiveram menor desenvolvimento da planta, que por não ter sua exigência nutricional suprida não pode apresentar seu máximo potencial genético, com isso ela teve menor área foliar para fotossintetizar e seu produto final ser translocado para o colmo e aumentar o seu diâmetro.

Para o ganho de matéria seca das raízes houve interferência direta do fator profundidade de deposição do adubo. Tanto para a profundidade de semeadura $3-5 \mathrm{~cm}$, os melhores resultados foram encontrados quando o adubo foi depositado a $18 \mathrm{~cm}$ de profundidade. Entretanto, o melhor resultado foi encontrado na semeadura a $3 \mathrm{~cm}$ com profundidade de adubo a $18 \mathrm{~cm}$ (Tabela 4).

Tabela 4. Matéria Seca das Raízes em função da profundidade de plantio e profundidade de deposição do adubo, CPCE/UFPI, Bom Jesus-PI.

\begin{tabular}{ccc}
\hline $\begin{array}{c}\text { Profundidade } \\
\text { do Adubo }\end{array}$ & \multicolumn{2}{c}{ Profundidade de semeadura } \\
\hline $\mathbf{3 ~ c m}$ & $\mathbf{5} \mathbf{~ c m}$ \\
$\mathbf{0}$ & $38.8 \mathrm{Ca}$ & $36.1 \mathrm{Cb}$ \\
$\mathbf{6}$ & $53.6 \mathrm{Ba}$ & $47.4 \mathrm{Bb}$ \\
$\mathbf{1 2}$ & $56.3 \mathrm{Ba}$ & $48.9 \mathrm{Bb}$ \\
$\mathbf{1 8}$ & $66.7 \mathrm{Aa}$ & $59.7 \mathrm{Ab}$ \\
\hline $\mathbf{C V} \%$ & &
\end{tabular}

C.V.\%: coeficiente de variação experimental; ${ }^{1}$ médias seguidas de mesma letra maiúscula na coluna e minúscula na mesma linha e época não diferem entre si pelo teste de Tukey $(\mathrm{p}<0,05)$.

Isso pode ser explicado pelo fato da planta possuir mecanismo que em condições de deficiência nutricional, diminui ou cessa o seu crescimento vegetativo e aumenta a produção e crescimento de raízes para obtenção de água e nutrientes, o que demanda um gasto energético da planta. Quando toda a exigência hídrica e nutricional está disponível superficialmente, próximo a raiz, a planta não precisa ter esse gasto energético com a produção e crescimento de raízes porque o que ela necessita está ao seu pronto alcance. No presente trabalho para as duas profundidades de semeadura as médias encontradas na profundidade de adubo a 6 e $12 \mathrm{~cm}$ tiveram um menor valor inferior ao tratamento de 18 $\mathrm{cm}$.

Em relação a profundidade de semeadura, todos os tratamentos a $3 \mathrm{~cm}$ tiveram média significativa superior a semeadura de $5 \mathrm{~cm}$ para uma mesma profundidade de deposição do adubo, provando que uma semeadura mais rasa influi positivamente para o maior 
desenvolvimento radicular e que o adubo mais profundo induz a planta a desenvolver mais seu sistema radicular proporcionado maior resistência ao acamamento e melhor desenvolvimento da parte aérea (BIULCHI, 2012).

Na tabela 5 são apresentados os valores médios do peso da parte aérea. Nota-se que o peso seco da parte aérea apresenta os mesmos resultados de modo geral da tabela 2 que mostra a altura das plantas, uma vez que as plantas que tiveram maior altura apresentaram também o maior peso seco de parte aérea consequentemente, pois a altura da planta possui ligação íntima com a produtividade de massa seca (MELLO et al., 2004).

$\mathrm{O}$ aumento da profundidade de deposição do adubo interferiu negativamente no peso seco da parte aérea. Para a parte aérea, o peso seco foi maior na profundidade de $6 \mathrm{~cm}$, quanto comparado aos demais tratamentos. Isso pode ser explicado pelo fato das plantas terem um gasto maior para produção e crescimento da zona radicular, diminuindo o seu crescimento vegetativo.

Tabela 5. Matéria seca da Parte Aérea em função da profundidade de plantio e profundidade de deposição do adubo, CPCE/UFPI, Bom Jesus-PI

\begin{tabular}{ccc}
\hline $\begin{array}{c}\text { Profundidade } \\
\text { do Adubo }\end{array}$ & $\mathbf{3} \mathbf{~ c m}$ & $\mathbf{5} \mathbf{~ c m}$ \\
\hline & & \\
$\mathbf{0}$ & $11,9 \mathrm{Da}$ & $11,5 \mathrm{Da}$ \\
$\mathbf{6}$ & $60,6 \mathrm{Aa}$ & $58,12 \mathrm{Ab}$ \\
$\mathbf{1 2}$ & $51 \mathrm{Ba}$ & $37,83 \mathrm{Bb}$ \\
$\mathbf{1 8}$ & $46,5 \mathrm{Ca}$ & $18,8 \mathrm{Cb}$ \\
\hline
\end{tabular}

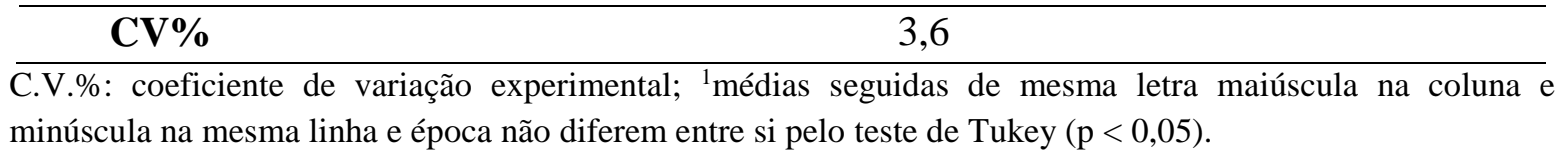

A Tabela 5 mostra ainda, que houve diferença significativa entre as profundidades, com exceção a testemunha, sendo que os tratamentos a $3 \mathrm{~cm}$ de profundidade apresentaram as maiores médias de peso seco da parte aérea quando comparadas aos tratamentos que foram semeados a $5 \mathrm{~cm}$, que tiveram uma emergência e estabelecimento mais demorado devido a maior profundidade de semeadura e portanto menor tempo para desenvolver sua parte aérea em comparação as que foram semeadas a $3 \mathrm{~cm}$.

\section{CONCLUSÃO}

1- Para todas a profundidades de adubação a semeadura a $3 \mathrm{~cm}$ proporcionou resultados superiores ao de $5 \mathrm{~cm}$ para as análises de altura de planta, diâmetro de colmo e peso da matéria seca da parte aérea;

2- Para as variáveis altura de planta, diâmetro do colmo e matéria seca da parte aérea, a profundidade de $6 \mathrm{~cm}$ do adubo associado com a semeadura a $3 \mathrm{~cm}$ foram as que apresentaram os melhores resultados;

Cultura Agronômica, Ilha Solteira, v.27, n.1, p.91-100, 2018 
3- A massa seca das raízes apresentou um melhor resultado na profundidade de adubação de $18 \mathrm{~cm}$, com semeadura a $3 \mathrm{~cm}$;

4- A testemunha apresentou as menores médias para todas as avaliações nos tratamentos de profundidade de deposição de adubo e profundidade de semeadura.

\section{REFERÊNCIAS BIBLIOGRÁFICAS}

ANDERSSON, C. Avaliação técnica de semeadoras-adubadoras para plantio direto. Plantio Direto, Passo Fundo, n. 66, p.28-32, 2001.

BIULCHI, P. V. Resposta da cultura do milho a profundidade de deposição de adubo e de culturas de cobertura em solo de cerrado. 2012. 63 f. Tese (Doutorado em Agronomia) - Faculdade de Ciências Agrárias e Veterinárias, Universidade Estadual Paulista, Jaboticabal, 2012.

CAI, H.; MA, W.; ZHANG, X.; PING, J.; YAN, X.; LIU, J.; REN, J. Effect Of Subsoil Tillage Depth On Nutrient Accumulation, Root Distribution, And Grain Yield In Spring Maize, Crop Journal, v. 2, n. 5, p.297-307, 2014.

COMPANHIA NACIONAL DE ABASTECIMENTO - CONAB. Acompanhamento da safra brasileira de grãos. 8 ed. Brasília: Conab, 2016. 166 p.

CRUZ, J. C.; FILHO, I. A. P.; ALVARENGA, R. C.; NETO, M. M. G.; VIANA, J. H. M.; OLIVEIRA, M. F.; MATRANGOLO, W. J. R.; ALBUQUERQUE FILHO, M. R. Cultivo do Milho. Sete Lagos: Embrapa Milho e Sorgo, 2010. 10 p.

CRUZ, J. C.; PEREIRA FILHO, I. A.; PIMENTEL, M. A. G.; COELHO, A. M.; KARAM, D.; CRUZ, I.; GARCIA, J. C.; MOREIRA, J. A. A.; OLIVEIRA, M. F.; GONTIJO NETO, M. M.; ALBUQUERQUE, P. E. P.; VIANA, P. A.; MENDES, S. M.; COSTA, R. V.; AlvarengA, R. C.; MAtrangolo, W. J. R. Produção de milho na agricultura familiar. Sete Lagoas: Embrapa Milho e Sorgo, 2011. 45 p.

DURÃES, F. O. M. Limitações fisiológicas do milho nas condições de plantio nas regiões tropicais baixas. 2007. Artigo em Hypertexto. Disponível em: <http://www.infobibos.com/Artigos/2007_1/limitemilho/index.htm>. Acesso em: 01 fev. 2018.

GOMES, M. T; SILVA, A. A. P; MATIAS, J. P; MACIEL, C. D. G; KARPINSKI, R. A. K. Germinação de sementes de milho com e sem aplicação de acetato de zinco em diferentes profundidades de semeadura. Campo Digital, Campo Mourão, v. 11, n. 1, p.33-41, 2016.

GUARESCHI, R. F.; PERIN, A.; GAZOLLA, P. R. Produtividade de milho submetido à aplicação de ureia revestida por polímeros. Global Science and Technology, Rio Verde, v. 7, n. 2, p.1-7, 2013.

MELLO, R.; NÖRNBERG, J. L.; ROCHA, M. G. Potencial produtivo e qualitativo de híbridos de milho, sorgo e girassol para ensilagem. Revista Brasileira de Agrociência,

Cultura Agronômica, Ilha Solteira, v.27, n.1, p.91-100, 2018 
Pelotas, v. 10, n. 1, p.87-95, 2004.

NUMMER, I.; GRIECO, J. Híbridos marca Pioneer® com a tecnologia Leptra® estão trazendo novos patamares de produtividade no campo. Revista Pionner, v. 42, p.5-7, 2016.

SILVA, R. P; CORÁ, J. E.; FILHO, A. C.; FURLANI, C. E. A.; LOPES, A. Efeito da profundidade de semeaduras e de rodas compactadoras submetidas a cargas verticais na temperatura e no teor de água do solo durante a germinação de sementes de milho. Ciência e Agrotecnologia, Lavras, v. 32, n. 3, p.929-937, 2008.

SILVA, R. P. Efeito de rodas compactadoras submetidas a cargas verticais em profundidades de semeadura nas características agronômicas do Milho (Zea mays L.). 2002. 101 f. Tese (Doutorado em Produção Vegetal) - Faculdade de Ciências Agrárias e Veterinárias, Universidade Estadual Paulista, Jaboticabal, 2002.

SOUZA, S. R.; FERNANDES, M. S. Nitrogênio. In: FERNANDES, M. S. (Ed.) Nutrição Mineral de Plantas. Viçosa: Sociedade Brasileira de Ciência do Solo, 2006. cap. 9, p. 216252. 